\title{
Effect of oral contraceptives intake on postural stability in young healthy women throughout the menstrual cycle
}

\author{
Miroslava Mokošáková ${ }^{1,2}$, Tomáš Senkoํㅜ, Monika Okuliarová1, Lucia Kršková ${ }^{1}$, František \\ Hlavačka ${ }^{2}$ and Michal Zeman ${ }^{1}$ \\ ${ }^{1}$ Department of Animal Physiology and Ethology, Faculty of Natural Sciences, Comenius University, Bratislava, Slovakia \\ ${ }^{2}$ Laboratory of Motor Control, Institute of Normal and Pathological Physiology, Slovak Academy of Sciences, Bratislava, \\ Slovakia
}

\begin{abstract}
The purpose of the study was to investigate the effect of oral contraceptives on static postural stability in young healthy women during their menstrual cycle. Twenty-three women with the regular menstrual cycle, using or not using oral contraceptives, participated in this study. Salivary progesterone and estradiol levels were measured during one menstrual cycle. Measurements of balance were performed during a quiet stance on a firm and foam surface by the force platform, with eyes either opened or closed, on day 2, 7, 14, 21 and 28 of the cycle. Results of stability on a firm surface with eyes opened showed a significant effect in the amplitude of body sway in the anterior-posterior direction since women using oral contraceptives had a lower amplitude compared to control women on day 28. During stance on a firm surface with eyes closed we showed only impact of the menstrual cycle on postural stability of women. In condition of stance on foam surface with the eyes opened or closed no significant effects were found. Our results showed that oral contraceptives intake can improve the static postural stability before the onset of menstruation and decrease a risk of injury of young healthy women.
\end{abstract}

Key words: Postural stability - Menstrual cycle - Oral contraceptives

\section{Introduction}

Concentrations of female sex hormones (estrogens and progesterone) fluctuate during the menstrual cycle and in addition to reproductive function they can affect different control systems. Among them, postural control in women can be influenced by cyclic hormonal changes; however, there are controversial data in the literature. Several studies support a role for changing concentrations of circulating estrogens and progesterone in postural control (Naessen et al. 1997; Hayashi et al. 2004; Ekenros et al. 2011; Shahin et al. 2012), while other studies did not find such a relationship (Hertel et al. 2006; Abt et al. 2007).

Oral contraceptives stabilize hormone levels during the menstrual cycle and can improve neuromuscular coordina-

Correspondence to: Miroslava Mokošáková, Department of Animal Physiology and Ethology, Faculty of Natural Sciences of Comenius University, Mlynská dolina, Ilkovičova 6, 842 15, Bratislava 4, Slovakia E-mail: miroslavamokosakova@gmail.com tion in women (Möller-Nielsen and Hammar 1991). Sex hormones were reported to increase joint laxity and decrease neuromuscular performance and in this way either passively or actively stabilize joints, and as a result, affect postural balance (Hewett 2000).

Estrogens and progesterone can play their role in the postural control acting also on the central nervous system, outside areas related to the control of reproductive processes (Al-Dahan and Thalmann 1996; Woolley 1999; Darlington 2009). The presence and distribution of receptors for both hormones have been demonstrated in the brainstem and the cerebellum and therefore sex hormones may influence balance and motor function (Darlington 2009). Moreover, hormonal alterations during the menstrual cycle may compromise the homeostasis of labyrinthic fluids and alter balance (Ishii et al. 2009).

Cyclical mood and physical changes are seen in 75 to $90 \%$ of all women of fertile age (Sveindóttir and Bäckström 2000). The premenstrual syndrome (PMS) is well known as a period, during women have symptoms that appear at 
the time of ovulation or thereafter which are significantly improved with the onset of menstruation and disappear by the conclusion of the bleed (Pariser et al. 1985). Features commonly associated with the PMS are irritability, mastodynia, bloating, cramps, headaches, insomnia, appetite changes, alterations in libido and fatigue (Reid and Yen 1981; Bancroft and Bäckström 1985). Oral contraceptives use is associated with a lower risk of experiencing many, but not all premenstrual symptoms, this effect may be dependent on the nature and severity of the symptom (Jarosz et al. 2017). Some of these symptoms and alterations may influence the performance of daily activities and can lead to impaired stability in women (Möller-Nielsen and Hammar 1991; Fridén et al. 2003; Fridén et al. 2005).

Knowledge about effects of oral contraceptive intakes on static postural balance during the menstrual cycle is limited. Therefore, the major aim of our study was to verify an impact of the menstrual cycle on postural stability of women and to find whether the static postural stability over the cycle differs between women using or not using oral contraceptives.

\section{Materials and Methods}

\section{Subjects}

Twenty-three young healthy women were included in the study, separated into the control group (CTRL; $n=11$ ) and women using combined oral contraceptives (estrogen and progestin) (OC; $n=12$; Table 1 ). None of the volunteers reported any disease or injury associated with neurological, orthopedic or balance impairments, or any irregularities of their menstrual cycle which could impair balance and/or interfere with the assessment of the menstrual cycle. Control women did not use oral contraceptives or any other hormonal treatment for at least three months before entering the study. Women taking oral contraceptives had been using a stable type of contraception for at least for three months before entering and throughout the study. None of the subjects had been taking any medicine that could influence postural stability. Subjects were nonsmokers and were asked to refrain from

Table 1. Biometrical characteristics of control women $(n=11)$ and women using oral contraceptives $(n=12)$

\begin{tabular}{lcc}
\hline & Controls & Oral contraceptives \\
\hline Age (years) & $24.64 \pm 1.52$ & $23.33 \pm 0.92$ \\
Weight (kg) & $64.00 \pm 2.45$ & $57.08 \pm 1.73^{\star}$ \\
Height (m) & $1.71 \pm 0.02$ & $1.68 \pm 0.02$ \\
BMI & $21.75 \pm 0.88$ & $20.23 \pm 0.33$ \\
\hline
\end{tabular}

Data are means \pm SEM. Differences between groups were evaluated by Mann-Whitney test; ${ }^{*} p<0.05$ vs. Controls. consuming alcohol for $24 \mathrm{~h}$ before each measurement and had regular sleep-wake cycle during the monitored menstrual cycle. The study was approved by the local ethics committee. Written informed consent in agreement with the Declaration of Helsinki was obtained from all participants.

\section{Instrumentation and measurements}

The timing of the measurements was based on the participant's knowledge of her menstrual cycle length. Women were asked to come on the particular day of their menstrual cycle. Measurements of balance were performed on day 2 (on the second day of menses), 7 (in the midfollicular phase), 14 (around the time of ovulation), 21 (in the midluteal phase) and 28 (the day before initiating a new cycle) of the menstrual cycle ( \pm 1 day).

During one menstrual cycle, five postural measurements were performed in the morning for each participant using a force platform. For each measurement, the postural test consisted of four conditions: quiet stance on a firm surface with eyes opened (EO) and closed (EC), stance on a foam surface (thickness $10 \mathrm{~cm}$ ) with eyes opened (FEO) and closed (FEC). The conditions were presented to the subjects in random order. The participants were asked to stand upright and relaxed, arms along the body, barefoot, the heels together with feet at a $30^{\circ}$ angle. Under conditions with open eyes, the subjects were instructed to look at a black point (with a diameter of $2 \mathrm{~cm}$ ) placed at eye level on a white wall a distance of 1.5-2 $\mathrm{m}$ away. During the subsequent test, the subjects had their eyes closed. The beginning and the end of each trial was recorded. Each measurement took $50 \mathrm{~s}$, during which the subjects were not allowed to talk or move.

\section{Hormonal changes during the menstrual cycle}

To monitor changes of sex hormones during the menstrual cycle, salivary progesterone and estradiol levels were measured in representative groups of control women $(n=6)$ and women using oral contraceptives $(n=8)$. Unstimulated saliva specimens were collected in the morning before the meal and tooth brushing every two days during the menstrual cycle. The samples were stored at $-20^{\circ} \mathrm{C}$ until hormone analysis.

Salivary progesterone and estradiol concentrations were determined with enzyme-linked immunosorbent assay (ELISA) using commercial kits according to the manufacturer instructions (DRG, International, Inc., USA). All samples were run in two assays with intra-assay variation coefficients of $12.3 \%$, and $1.4 \%$ and inter-assay variation coefficients of $15.2 \%$ and $11.7 \%$ for progesterone and estradiol, respectively.

For each woman, means of progesterone and estradiol levels for the first and the second half of the follicular phase and the luteal phase of the menstrual cycle were calculated and used in the statistical analysis. 


\section{Data analysis}

Postural stability was quantified by the displacement of the center of pressure (COP) in the anterior-posterior (AP) and in the medial-lateral (ML) directions, measured by the custom-made force platform with three inbuilt force transducers, equipped with automatic correction of the subject's weight (Abrahámová and Hlavačka 2008). Direct COP output signals in the AP and ML directions were collected with a $100 \mathrm{~Hz}$ sampling frequency and low-pass filtered with a cut-off frequency of $10 \mathrm{~Hz}$. Data were analyzed using the MATLAB software (MathWorks Inc., Natick, MA). After processing the data, we obtained the following postural parameters: $\mathrm{A}_{\mathrm{AP}} \mathrm{A}_{\mathrm{ML}}(\mathrm{cm})$, the amplitude of the body sway in the $\mathrm{AP}$ and $\mathrm{ML}$ directions; $\mathrm{V}_{\mathrm{AB}} \mathrm{V}_{\mathrm{ML}}(\mathrm{cm} / \mathrm{s})$, the velocity of the body sway in the AP and ML directions; RMS (cm), the root mean square and TA $\left(\mathrm{cm}^{2}\right)$, the total area of the statokinesigram. The parameters RMS and TA characterize the overall stability of the upright posture independently on the direction of postural sway (Hlavačka et al. 1990).

\section{Statistical analysis}

Statistical processing of the data was performed in the program Statistica 7.0 (StatSoft Inc., USA). Paired t-test and repeated measures analysis of variance (ANOVA) were used to analyze hormonal changes between the follicular and luteal phases of the menstrual cycle. Two-way ANOVA with repeated measures and Fisher's LSD post hoc tests was used to analyze postural stability measures with "oral contraceptives use" as the between effect and "the stage of the menstrual cycle" as the within effect. $p<0.05$ are considered significant and data are presented as means \pm SEM (standard error of mean).

\section{Results}

Progesterone concentrations in saliva were significantly higher in the luteal as compared to both the first and the second half of the follicular phase in control women $\left(F_{(5,10)}=21.58 ; p<0.001\right)$ and did not vary between both phases in women using oral contraceptives $\left(\mathrm{F}_{(7,14)}=0.07 ; p=\right.$ 0.93 ; Table 2). Salivary estradiol concentrations significantly varied during the menstrual cycle in control women $\left(\mathrm{F}_{(2,10)}=\right.$ 6.01; $p<0.05)$ showing higher levels in both the luteal and the second half of the follicular phase as compared to the first half of the follicular phase (Table 2). In women using oral contraceptives, estradiol levels exhibited no variability during the menstrual cycle $\left(\mathrm{F}_{(2,4)}=0.40 ; p=0.70\right)$.

We observed significant differences in the amplitude of body sway in the AP direction in the condition of stance on a firm surface with open eyes (Fig. 1A). Two-way ANOVA with the day of the cycle as a repeated measure revealed significant differences in the interaction group $\mathrm{x}$ cycle $\left(\mathrm{F}_{(4,84)}\right.$ $=2.57 ; p=0.044)$. Women using oral contraceptives had lower amplitude compared to control women on day 28 $(p<0.05)$. Significant differences were recorded within the control group, the increased amplitude from day 2 to day 14 $(p<0.05)$ and a subsequent decrease to day $21(p<0.05)$. In women using oral contraceptives, the lowest amplitude was found on day 28 as compared with day $2(p<0.05$; Fig. $1 \mathrm{~A})$. For the amplitude of body sway in the ML direction in the condition of stance on a firm surface with open eyes, we did not observe any differences either between groups or in the interaction group $\mathrm{x}$ cycle (Fig. 1B). In the condition of stance on a firm surface with closed eyes, both groups exhibited a similar pattern in the amplitude of body sway in the AP and ML directions throughout the menstrual cycle. We observed significant differences in the amplitude of body sway in the $\operatorname{AP}\left(\mathrm{F}_{(4,84)}=2.52 ; p=0.047\right.$; Fig. $\left.1 \mathrm{C}\right)$ and $\mathrm{ML}$ directions $\left(\mathrm{F}_{(4,84)}=2.62 ; p=0.041\right.$; Fig. 1D) regardless of the group. A significantly higher amplitude of body sway in the AP direction was found on day 2 in comparison with day $7(p<0.01)$ and day $28(p<0.05)$ of the menstrual cycle (Fig. 1C). The amplitude of body sway in the medial-lateral direction peaked at day 21 , with significantly higher values in comparison with day $7(p<0.01)$, day $14(p<0.05)$ and day $28(p<0.05)$ of the menstrual cycle (Fig. 1D).

In the condition of stance on a firm surface with opened eyes, we did not observe significant differences in the velocity of body sway in the AP and ML directions in either group (Fig. 2A, B). The elimination of visual input led to in significant differences in the velocity of body sway in the

Table 2. Salivary progesterone and estradiol levels in control women $(n=6)$ and women using oral contraceptives $(n=8)$ during the first (FP1) and the second (FP2) half of the follicular phase and the luteal phase (LP) of the menstrual cycle

\begin{tabular}{lcccc}
\hline \multirow{2}{*}{$\begin{array}{l}\text { Menstrual } \\
\text { cycle phase }\end{array}$} & \multicolumn{2}{c}{ Controls } & \multicolumn{2}{c}{ Oral contraceptives } \\
\cline { 2 - 3 } \cline { 5 - 5 } FP1 & $71.0 \pm 8.5$ & Estradiol $(\mathrm{pg} / \mathrm{ml})$ & & Progesterone $(\mathrm{pg} / \mathrm{ml})$ \\
FP2 & $76.0 \pm 11.8$ & $4.0 \pm 0.4$ & $61.8 \pm 6.9$ & $3.1 \pm 0.4$ \\
LP & $182.1 \pm 29.3^{* * *}$ & $5.4 \pm 0.4^{* *}$ & $61.2 \pm 8.2$ & $3.6 \pm 0.9$ \\
\hline
\end{tabular}

Data are means \pm SEM. ${ }^{\star} p<0.05,{ }^{* *} p<0.01$ vs. of estradiol in FP1 phase; ${ }^{* * *} p<0.001 v s$. progesterone in FP1 and FP2 phase. 
AP direction $\left(\mathrm{F}_{(4,84)}=3.10 ; p=0.0197\right.$; Fig. $\left.2 \mathrm{C}\right)$ and $\mathrm{ML}$ direction $\left(\mathrm{F}_{(4,84)}=3.20 ; p=0.017\right.$; Fig. 2D). Throughout the menstrual cycle, women in both groups exhibited a lower velocity in the AP direction on day 7 in comparison with day 14 and day 21 ( $p<0.01$; Fig. 2C). In the ML direction, the highest velocity was recorded on day 21 as compared to day 7 and day 28 ( $p<0.01$; Fig. 2D). Using contraception did not influence velocity parameters either with the subject's eyes opened or closed.

In the condition of stance on a firm surface with opened eyes, we did not observe significant differences in the root mean square and total area of the statokinezigram in either group (Fig. 3A, B). Significant differences in the parameter RMS during the cycle were revealed in condition of stance on a firm surface with closed eyes $\left(\mathrm{F}_{(4,84)}=3.0544 ; p=\right.$ 0.0211; Fig. 3C). Women, regardless of whether they used contraceptives or not, had lower RMS on day 7 compared to day $2(p<0.01)$ and day $21(p<0.05)$. Higher values were recorded on day 2 compared to day 28 of the menstrual cycle $(p<0.05$; Fig. $3 C)$. Significant differences in the parameter TA during the cycle were revealed in condition of stance on a firm surface with closed eyes $\left(\mathrm{F}_{(4,84)}=3.8327\right.$; $p=0.0065$; Fig. 3D). Both groups had lower TA on day 7 , values increased until day 21 , then declined to day 28 of the cycle (Fig. 3D).

In condition of stance on a foam surface with the eyes opened (FEO) or closed (FEC) no significant effects were found (results are not included).
A

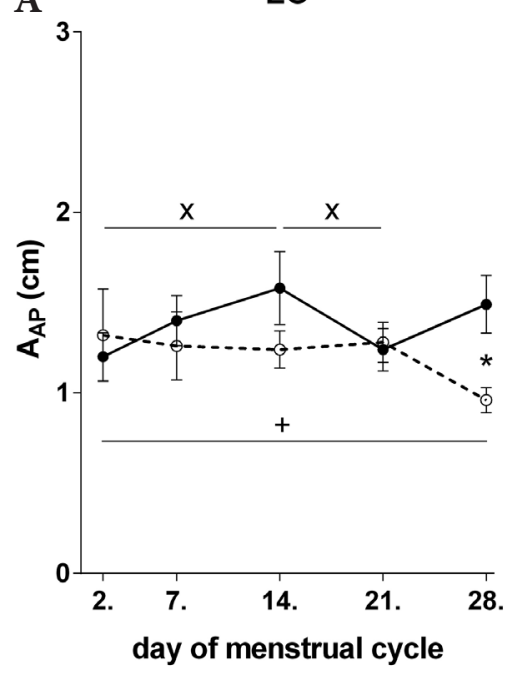

C

EC

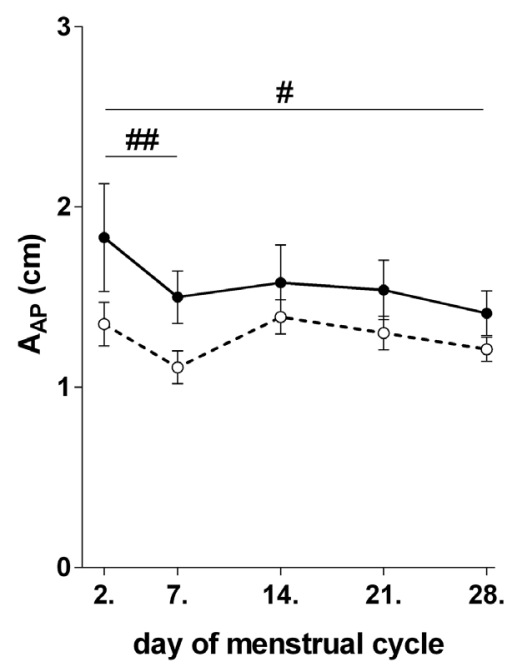

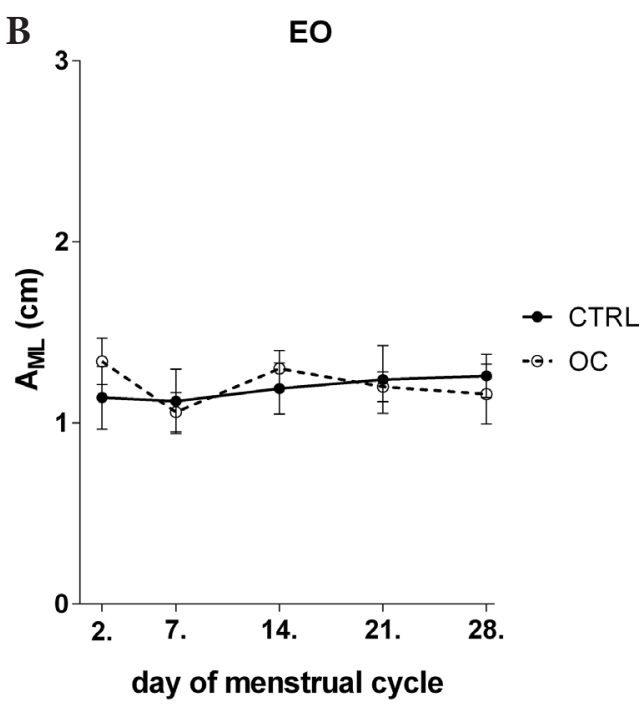

D

EC

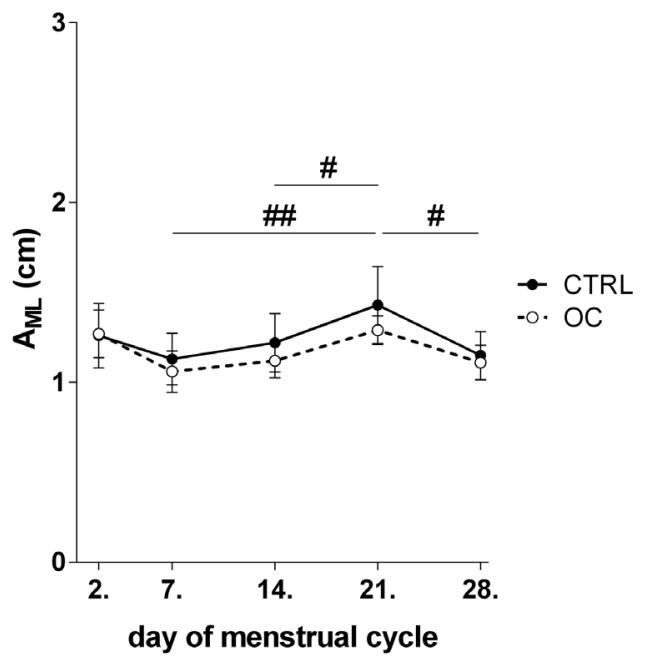

Figure 1. The amplitude of body sway in the anteriorposterior direction $\left(\mathrm{A}_{\mathrm{AP}} ; \mathbf{A}\right.$, C) and in the medial-lateral direction $\left(\mathrm{A}_{\mathrm{ML}} ; \mathbf{B}, \mathrm{D}\right)$ in condition of stance on a firm surface with eyes open (EO) and closed (EC) during the menstrual cycle. Data are means \pm SEM. ${ }^{*} p<0.05$ differences between groups; ${ }^{\mathrm{x}} p<0.05$ differences within control women; ${ }^{+} p<0.05$ differences within women using oral contraceptives; ${ }^{\#} p<$ $0.05, \#$ \# $p<0.01$ differences between day of the cycle regardless of the groups. CTRL, control women; OC, women using oral contraceptives. 


\section{Discussion}

In the condition of stance on firm surface with open eyes, we found the maximal amplitude of the body sway in AP direction at day 14 , during the time of expected ovulation in control women, with a subsequent decrease in the midluteal phase. Day 21 was characterized by high progesterone and estradiol levels. Increased postural instability during the time of ovulation in our study may reflect a hormonal imbalance when the negative feedback control between estrogens and luteinizing hormone is changing to positive feedback and the release of gonadotropins and gonadotropin releasing hormone is maximal (Mihm et al. 2011; Olive and Palter 2012). In the amplitude of the lateral sway we did not find any effect. Interestingly, Darlington et al. (2001) found effects of the menstrual cycle only on lateral sway. In their study, lateral sway on day 5 was greater than on day 12 and 21 , and on day 25 it was greater than on day 21 . Day 5 corresponds to a low level of estrogens and progesterone, while day 25 corresponds to declining levels of both hormones (Darlington et al. 2001).

Women using oral contraceptives had lower amplitude of body sway in AP direction in the condition of stance on firm surface with open eyes as compared to control women on day 28. The lower amplitude of body sway before the onset of menstruation in women using oral contraceptives indicated a positive effect of contraceptives on postural stability. The positive effect can be caused by the suppression of natural sex hormone biosynthesis and release by oral contraceptives (Agel et al. 2006; Fleischman et al. 2010). In contrast, the impaired postural stability of control women at this phase of the cycle could be explained by PMS. It has been reported
A

EO

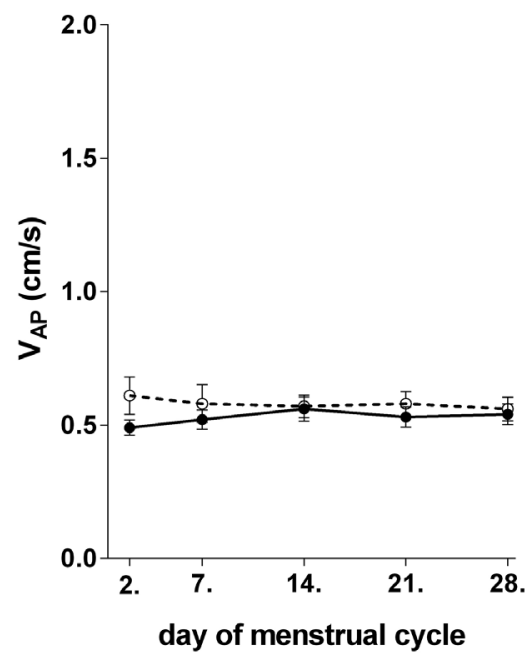

C

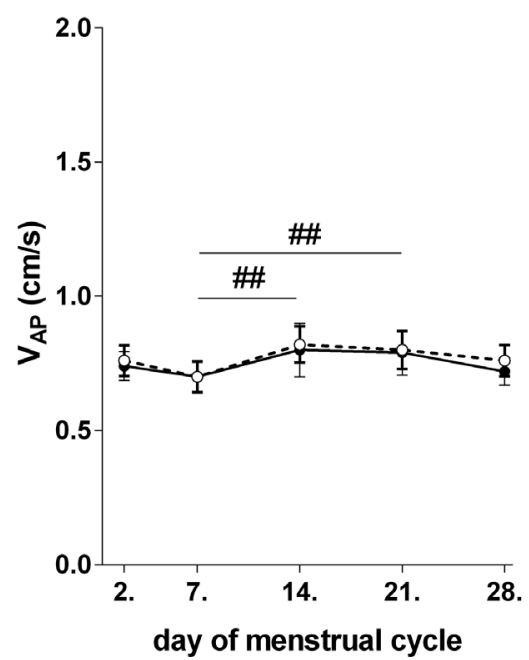

B

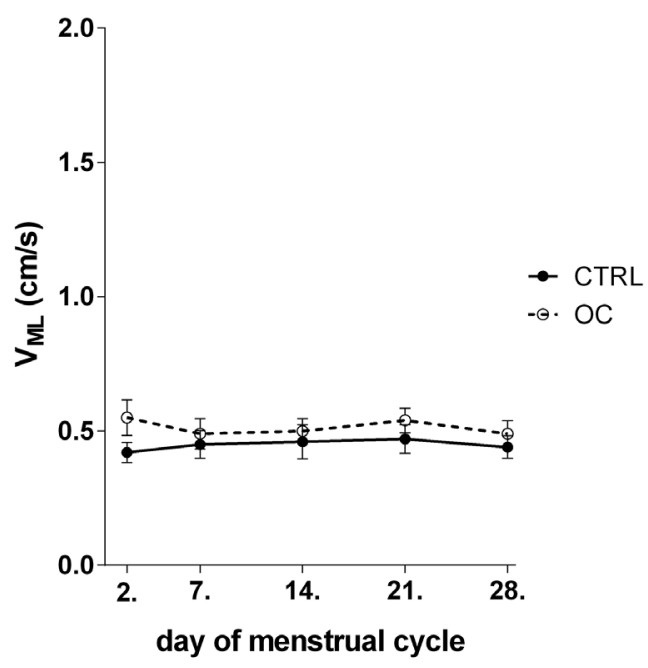

D

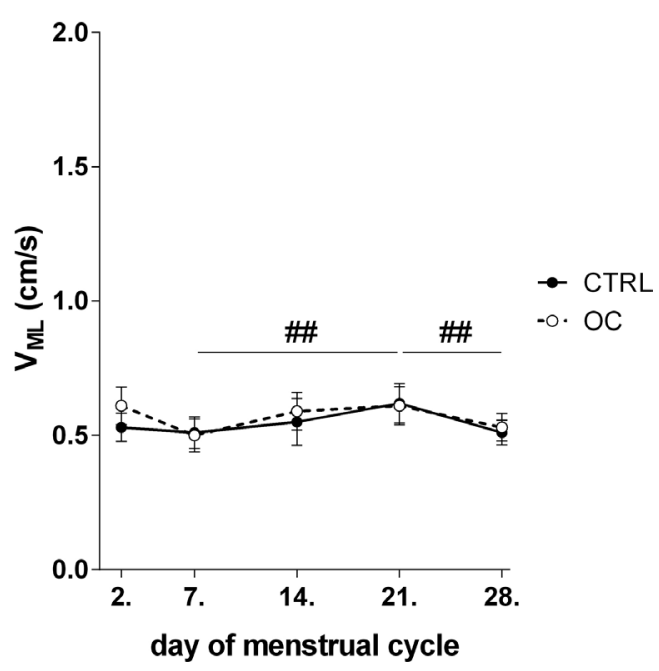

Figure 2. The velocity of body sway in the anteriorposterior direction $\left(\mathrm{V}_{\mathrm{AP}} ; \mathrm{A}\right.$, C) and in the medial-lateral direction $\left(\mathrm{V}_{\mathrm{ML}} ; \mathbf{B}, \mathbf{D}\right)$ in condition of stance on a firm surface with eyes open (EO) and closed (EC) during the menstrual cycle. Data are means \pm SEM. ${ }^{\# \#} p<0.01$ differences between day of the cycle regardless of the group. For abbreviations, see Fig. 1. 
that symptoms of PMS, such as impaired concentration and decreased psychomotor performance, can lead to impaired stability in women (Möller-Nielsen and Hammar 1991; Fridén et al. 2003; Fridén et al. 2005). Therefore, oral contraceptives use is associated with a lower risk of experiencing premenstrual symptoms (Jarosz et al. 2017) and this effect may improve postural stability.

In the condition of stance on firm surface with eyes closed we found effect of the menstrual cycle on postural stability in all stabilometric parameters regardless on the group of women. The amplitude of sway in both directions demonstrated impaired stability on day 2 , its improvement on day 7 , deterioration through the time of ovulation and the midluteal phase and a subsequent improvement before menstruation. Similarly, Demir and Muammer (2015) evaluated women during the first three days of their menstrual period and eight days after menstruation. They found that the balance was better after menstruation and their results are in line with our data on improved stability on day 7 . The velocity of sway in both directions had approximately the same course and values in both groups of women. The lowest velocity, i.e. the best postural stability, was found on day 7, while the highest velocity on day 21 . Additional parameters, RMS and the total area of the statokinezigram supported the better stability of women on day 7 and deterioration on day 21. These data suggest that the elimination of visual input increases the variability in postural control throughout the menstrual cycle and indicate that cyclic hormonal concentrations predominantly affect neuromuscular and vestibular control. Cyclic changes in estrogen and progesterone levels have already been associated with changes in various types of connective tissue, including joint ligaments, cartilage and bone (Cammarata and Dhaher 2008; Calleja-Agius and Brincat 2009). They increase joint laxity and decrease neuromuscular performance
A

EO

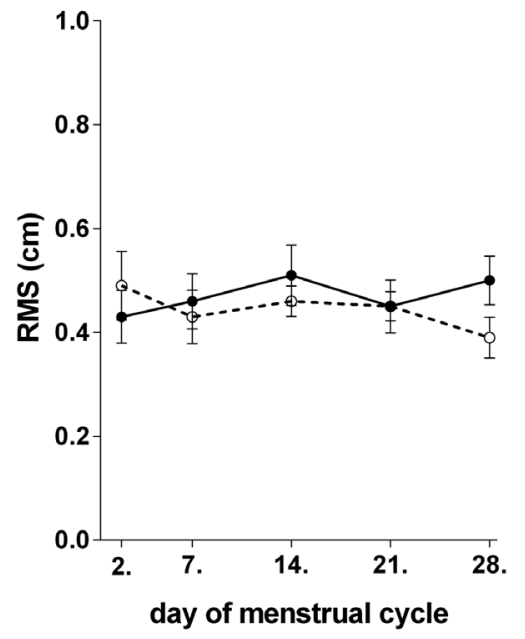

C

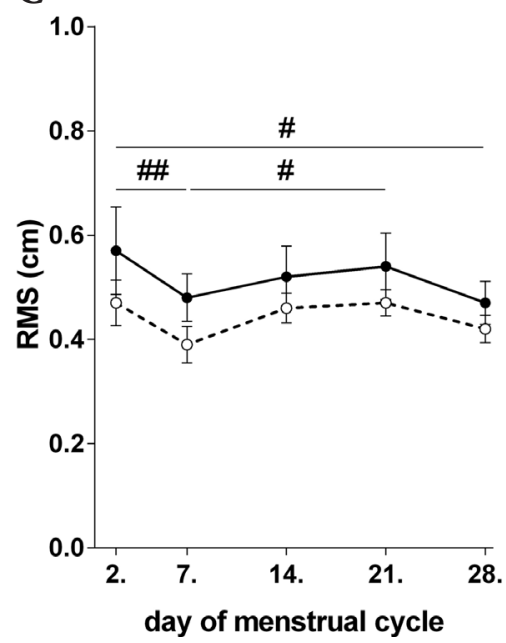

B

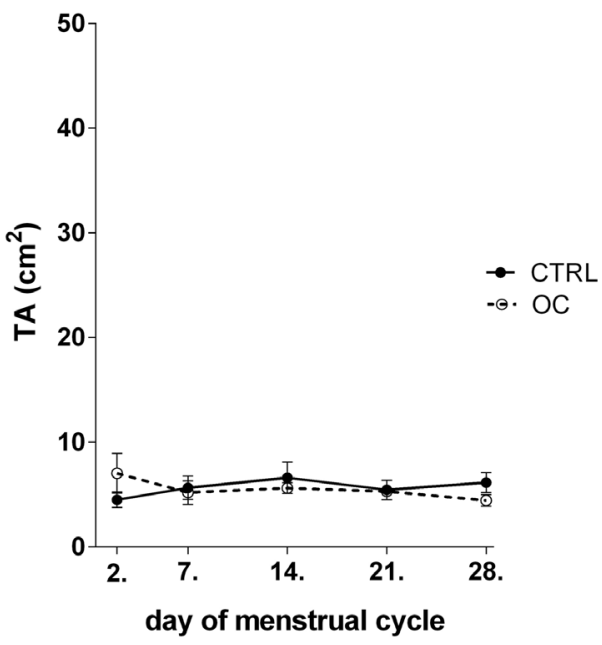

D

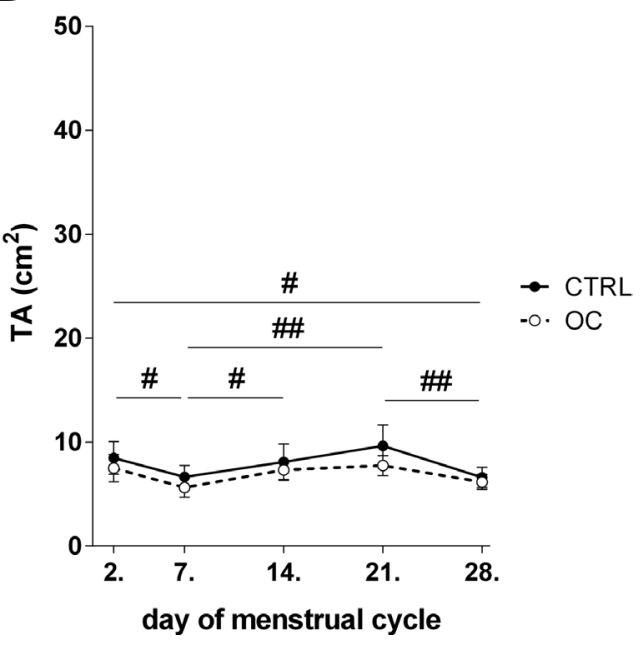

Figure 3. The root mean square (RMS; $\mathbf{A}, \mathbf{C}$ ) and the total area $(\mathrm{TA} ; \mathbf{B}, \mathrm{D})$ in condition of stance on a firm surface with eyes open (EO) and closed (EC) during the menstrual cycle. Data are means \pm SEM. ${ }^{\#} p<0.05 ;{ }^{\# \#} p<0.01$ differences between day of the cycle regardless of the group. 
and as a result can affect postural balance (Hewett 2000). In addition, estrogen receptors in skeletal muscles can affect neuromuscular control (Dedrick et al. 2008). The increased hormonal impact on soft tissue may influence joint stability and subsequently result in postural instability and injury (McLean et al. 2005; O’Sullivan et al. 2006). A high injury rate related to the menstrual cycle was demonstrated in a study by Ristolainen et al. (2009), who found twice as many injuries in sportswomen with irregular menstruation than in women with a regular menstrual cycle. Moreover, published results suggest that hormonal alterations during the menstrual cycle may compromise the homeostasis of labyrinthic fluids, since they act directly on enzymatic processes and have neurotransmitter effects (Ishii et al. 2009).

In both groups of women, in the conditions of stance on a foam surface with eyes opened and closed, we did not find any impact of menstrual cycle phase and oral contraceptives on postural stability. The data suggest that simultaneous exclusion of both visual and proprioceptive inputs eliminate effects of hormonal changes during the menstrual cycle on postural control. Our findings are in line with studies (Hertel et al. 2006; Abt et al. 2007).

In summary, the amplitude of body sway in AP direction during stance on a firm surface with eyes opened was lower on day 28 in women using oral contraceptives compared to control women. The elimination of visual input during stance on a firm surface showed an impact of the menstrual cycle on postural stability in both groups of women. Our results show that oral contraceptive intake can improve the static postural stability of young healthy women before the onset of menstruation as a result of reduced variability of hormonal levels and in this way can decrease a risk of injury.

Conflict of interest. The authors declare no conflicts of interests.

Acknowledgements. This work was supported by VEGA grants 1/0557/15, 2/0094/16 and 1/0824/17. We thank Mgr. Michaela Zimnáková for her help with saliva sample collection and processing.

\section{References}

Abrahámová D, Hlavačka F (2008): Age-related changes of human balance during quit stance. Physiol. Res. 57, 957-964

Abt JP, Sell TC, Laundner KG, McCrory JL, Loucks TL, Berga SL, Lephart SM (2007): Neuromuscular and biomechanical characteristics do not vary across the menstrual cycle. Knee Surg. Sports Traumatol. Arthrosc. 15, 901-907 https://doi.org/10.1007/s00167-007-0302-3

Agel J, Bershadsky B, Arendt EA (2006): Hormonal therapy: ACL and ankle injury. Med. Sci. Sports Exerc. 38, 7-12 https://doi.org/10.1249/01.mss.0000194072.13021.78

Al-Dahan MI, Thalmann RH (1996): Progesterone regulates gamma-aminobutyric acid $\mathrm{B}(\mathrm{GABAB})$ receptors in the neocortex of female rats. Brain Res. 727, 40-48 https://doi.org/10.1016/0006-8993(96)00338-1

Bancroft J, Bäckström T (1985): Premenstrual syndrome. Clin. Endocrinol. (Oxf). 22, 313-336

https://doi.org/10.1111/j.1365-2265.1985.tb03244.x

Calleja-Agius J, Brincat MP (2009): Effects of hormone replacement therapy on connective tissue: why is this important? Best Pract. Res. Clin. Obstet. Gynaecol. 23, 121-127

https://doi.org/10.1016/j.bpobgyn.2008.10.003

Cammarata ML, Dhaher YY (2008): The differential effects of gender, anthropometry, and prior hormonal state on frontal plane knee joint stiffness. Clin. Biomech. 23, 937-945 https://doi.org/10.1016/j.clinbiomech.2008.03.071

Darlington CL, Ross A, King J, Smith PF (2001): Menstrual cycle effects on postural stability but not optokinetic function. Neurosci. Lett. 307, 147-150 https://doi.org/10.1016/S0304-3940(01)01933-4

Darlington CL (2009): The Female Brain. CRC Press, Florida

Dedrick GS, Sizer PS, Merkle JN, Hounshell TR, Robert-McComb JJ, Sawyer SF, Brismée JM, Roger James C (2008): Effect of sex hormones on neuromuscular control patterns during landing. J. Electromyogr. Kinesiol. 18, 68-78 https://doi.org/10.1016/j.jelekin.2006.09.004

Demir A, Muammer R (2015): The effect of the menstruation period on static and dynamic balance and physical performance. Intl. J. Sport Std. 5, 636-641

Ekenros L, Hirschberg AL, Bäckström T, Fridén C (2011): Postural control in women with premenstrual symptoms during oral contraceptive treatment. Acta Obstet. Gynecol. Scan. 90, 97-102 https://doi.org/10.1111/j.1600-0412.2010.01021.x

Fleischman DS, Navarrete CD, Fessler DM (2010): Oral contraceptives suppress ovarian hormone production. Physiol. Sci. $21,750-752$ https://doi.org/10.1177/0956797610368062

Fridén C, Hirschberg AL, Saartok T, Bäckström T, Leanderson J, Renström P (2003): The influence of premenstrual symptoms on postural balance and kinesthesia during the menstrual cycle. Gynecol. Endocrinol. 17, 433-439 https://doi.org/10.1080/09513590312331290358

Fridén C, Ramsey DK, Bäckström T, Benoit DL, Saartok T, Hirschberg AL (2005): Altered postural control during the luteal phase in women with premenstrual symptoms. Neuroendocrinology 81, 150-157 https://doi.org/10.1159/000086592

Hayashi C, Ikeda M, Aizawa K, Murai F, Mesaki N (2004): Change in dynamic and static balance ability during menstrual cycle among young women. Jpn. J. Phys. Fitness Sports Med. 53, 197-204 https://doi.org/10.7600/jspfsm1949.53.197

Hertel J, Williams NI, Olmsted-Kramer LC, Leidy HJ, Putukian M (2006): Neuromuscular performance and knee laxity do not change across the menstrual cycle in female athletes. Knee Surg. Sports Traumatol. Arthrosc. 14, 817-822 https://doi.org/10.1007/s00167-006-0047-4

Hewett TE (2000): Neuromuscular and hormonal factors associated with knee injuries in female athletes. Strategies for intervention. Sports Med. 29, 313-327 https://doi.org/10.2165/00007256-200029050-00003 
Hlavačka F, Kundrát J, Križková M, Bačová E (1990): Physiological ranges of the values of parameters of the stomatitis examination of the upright posture evaluated by the computer. Čs. Neurol. Neurochir. 53, 107-113 (in Czech)

Ishii C, Nishino LK, Campos CA (2009): Vestibular characterization in the menstrual cycle. Braz. J. Otorhinolaryngol. 75, 375-380 https://doi.org/10.1016/S1808-8694(15)30655-8

Jarosz AC, Jamnik J, El-Sohemy A (2017): Hormonal contraceptive use and prevalence of premenstrual symptoms in a multiethnic Canadian population. BMC Womens Health. 17, 1-8 https://doi.org/10.1186/s12905-017-0450-7

McLean SG, Huang X, Vann den Bogert AJ (2005): Association between lower extremity posture at contact and peak knee valgus moment during sidestepping: implications for ACL injury. Clin. Biomech. 20, 863-870 https://doi.org/10.1016/j.clinbiomech.2005.05.007

Mihm M, Gangooly S, Muttukrishna S (2011): The normal menstrual cycle in women. Anim. Report. Sci. 124, 229-236 https://doi.org/10.1016/j.anireprosci.2010.08.030

Möller-Nielsen J, Hammar M (1991): Sports injuries and oral contraceptive use. Is there a relationship? Sports Med. 12, 152-160 https://doi.org/10.2165/00007256-199112030-00002

Naessen T, Lindmark B, Larsen HC (1997): Better postural balance in elderly women receiving estrogens. Am. J. Obstet. Gynecol. $\mathbf{1 7 7}, 412-416$ https://doi.org/10.1016/S0002-9378(97)70207-2

Olive DL, Palter SF (2012): Reproductive physiology. In: Berek and Novak's Gynecology (Eds. JS Berek), pp. 261-294, Lippincott Williams and Wilkins, Philadelphia

O’Sullivan PB, Mitchell T, Bulich P, Waller R, Holte J (2006): The relationship between posture and back muscle endurance in industrial workers with lexion-related low back pain. Man. Ther. 11, 264-271 https://doi.org/10.1016/j.math.2005.04.004

Pariser SF, Stern SL, Shank ML, Falko JM, O’Shaughnessy RW, Friedman CI (1985): Premenstrual syndrome: concerns, controversies, and treatment. Am. J. Obstet. Gynecol. 153, 599-604 https://doi.org/10.1016/S0002-9378(85)80241-6

Reid RL, Yen SSC (1981): Premenstrual syndrome. Am. J. Obstet. Gynecol. 139, 85-104 https://doi.org/10.1016/0002-9378(81)90417-8

Ristolainen L, Heinonen A, Waller B, Kujala UM, Kettunen JA (2009): Gender differences in sport injury risk and types of injuries: a retrospective twelve-month study on cross-country skiers, swimmers, long-distance runners and soccer players. JSSM 8, 443-451

Shahin A, Ulas YH, Deniz E (2012): Effects of menstrual periods on postural stability in eumenorrheic female group. Sci. Res. Essays 7, 3053-3057 https://doi.org/10.5897/SRE12.295

Sveindóttir H, Backström T (2000): Prevalence of menstrual cycle symptom cyclicity and premenstrual dysphoric disorder in a random sample of women using or not using oral contraceptives. Acta Obstet. Gynecol. Scand. 79, 405-413 https://doi.org/10.1080/j.1600-0412.2000.079005405.x

Woolley CS (1999): Effects of estrogen in the CNS. Curr. Opin. Neurobiol. 9, 349-354 https://doi.org/10.1016/S0959-4388(99)80051-8

Received: January 17, 2018

Final version accepted: May 12, 2018

First published online: July 26, 2018 